\title{
An Anti-Interference Online Monitoring Method for IGBT Bond Wire Aging
}

\author{
Chuankun Wang, Yigang He *, Yunfeng Jiang and Lie Li
}

Citation: Wang, C.; He, Y.; Jiang, Y.; Li, L. An Anti-Interference Online Monitoring Method for IGBT Bond Wire Aging. Electronics 2021, 10, 1449. https://doi.org/10.3390/ electronics10121449

Academic Editors: Ilgu Yun, Soon Il Jung, Chang Eun Kim and Edward Namkyu Cho

Received: 13 May 2021

Accepted: 10 June 2021

Published: 17 June 2021

Publisher's Note: MDPI stays neutral with regard to jurisdictional claims in published maps and institutional affiliations.

Copyright: (c) 2021 by the authors. Licensee MDPI, Basel, Switzerland. This article is an open access article distributed under the terms and conditions of the Creative Commons Attribution (CC BY) license (https:// creativecommons.org/licenses/by/ $4.0 /)$.
School of Electrical Engineering and Automation, Wuhan University, Wuhan 430072, China; wck980108@whu.edu.cn (C.W.); whujyf@sina.com (Y.J.); lilie@whu.edu.cn (L.L.)

* Correspondence: yghe1221@whu.edu.cn

\begin{abstract}
Due to the constant changes of the environment and load, the insulated-gate bipolar transistor (IGBT) module is subjected to a large amount of junction temperature $\left(T_{\mathrm{j}}\right)$ fluctuations, which often leads to damage to the bond wires. The monitoring parameters of IGBTs are often coupled with $T_{\mathrm{j}}$, which increases the difficulty of monitoring IGBTs' health status online. In this paper, based on the collector current $\left(I_{\mathrm{C}}\right)$ and collector-emitter on-state voltage ( $\left.V_{\text {ce_on }}\right)$ online monitoring circuit, an online monitoring method of IGBT bond wire aging against interference is proposed. First, the bond wire aging model is established, and the $V_{\text {ce_on }}$ is selected as the monitoring parameter. Secondly, taking a three-phase inverter circuit as an example, the $V_{\text {ce_on }}$ and $I_{\mathrm{C}}$ waveforms of the IGBT module are monitored in real time, and the process of online monitoring is introduced accordingly. Finally, the experimental results output by RT-LAB indicate that the method proposed in this paper can accurately identify the aging state of IGBT bond wires under different conditions.
\end{abstract}

Keywords: IGBT; bond wire aging; junction temperature; collector-emitter on-state voltage; online monitoring

\section{Introduction}

Compared with other power electronic devices, the insulated-gate bipolar transistor (IGBT) power module has many advantages, such as large input impedance, small driving power, a simple control circuit, small switching loss, and high working frequency, so it has been widely used in power converters [1,2]. In recent years, the application of power converters has been expanding, such as in wind power generation, solar power generation, electric vehicles, and aerospace power systems [3-6], which have harsh operating conditions and strict requirements for IGBT reliability. According to the reliability survey report of the converter system, the power semiconductor device is the component with the highest failure rate in the converter system, accounting for about 34\% of failures [7].

Due to the complex and changeable working conditions of the power converter, the IGBT is subjected to a large number of thermal stress, overvoltage, and overcurrent impacts in the process of operation [8,9]. Bond wire aging and solder layer aging are the two most common fatigue failure types of IGBT modules. On account of the different coefficients of thermal expansion (CTE) of the module materials, the thermal stress of the internal structure is uneven under temperature fluctuations, which eventually leads to damage to the bond wires and the solder layer [10-12]. The IGBT module can continue to operate for a period of time before complete failure. Therefore, if potential variations due to aging can be detected before complete failure, catastrophic failure can be avoided. In practical applications, the fatigue failure of IGBT modules is mostly manifested as the bond wires completely lift off $[13,14]$. IGBT bond wire aging monitoring is very necessary to improve the reliability of the converter, which is also the focus of this paper. Owing to the hindrance of the package structure of the IGBT module, it is difficult to directly monitor the aging process of bond wires. When the bond wire is broken, the equivalent parameters of the emitter area will change so that the external electrical parameters of the IGBT module 
will also change accordingly, which provides the possibility for condition monitoring. Therefore, some external electrical parameters with significant variations can be regarded as monitoring parameters for evaluating IGBT aging.

The existing monitoring parameters can be divided into the following categories:

1. Current-based parameter: short-circuit current $\left(I_{\mathrm{s}}\right)$. In [15], the authors took the $I_{\mathrm{S}}$ as the monitoring parameter for bond wire aging. When the number of broken bond wires in the IGBT module gradually increases, the $I_{\mathrm{s}}$ will decrease accordingly. However, this method needs to inject current into the IGBT module, which is not suitable for online monitoring application scenarios.

2. Time-based parameter: turn-on time $\left(t_{\mathrm{on}}\right)$ and turn-off time $\left(t_{\mathrm{off}}\right)$. The authors in $[16,17]$ calculated $t_{\text {on }}$ by measuring the current and voltage waveforms during IGBT turn-on and monitor bond wire failures accordingly. The experimental results show that the $t_{\text {on }}$ under the bond wire failure was shorter than that under the healthy state. In [18], the charging time of the gate capacitance was measured by injecting a small current during the IGBT turn-off period to monitor the health status of the bond wires. Since the switching time of the IGBT was in the range of 10-500 ns, the time-based parameters had extremely high requirements for the hardware measurement circuit.

3. Voltage-based parameter: gate voltage $\left(V_{\mathrm{g}}\right)$ and collector-emitter on-state voltage $\left(V_{\text {ce_on }}\right)$. In [19], the $V_{\text {ge }}$ was used to monitor the multi-chip parallel IGBT modules' health status. The experimental results showed that this method would not be affected by load current changes or noise caused by switching. However, only when all bond wires of a specific IGBT chip were broken did the $V_{\text {ge }}$ change significantly. The application of this method was limited to multi-chip parallel IGBT modules, which are not universal. The authors of $[20,21]$ cut the bond wire to simulate IGBT aging and monitor the IGBT health status by measuring $V_{\text {ce_on }}$ online. The results indicated that $V_{\text {ce_on }}$ could accurately identify the number of broken bond wires.

4. Temperature-based parameter: junction temperature $\left(T_{\mathrm{j}}\right)$ and thermal resistance $\left(R_{\mathrm{th}}\right)$. In [22], the case temperature $\left(T_{\mathrm{c}}\right)$ and junction temperature $\left(T_{\mathrm{j}}\right)$ were observed by thermocouples to calculate the $R_{\mathrm{th}}$. When the $R_{\mathrm{th}}$ increased by $20 \%$, the IGBT module failed. However, this method needs to invade the IGBT module package for measurement, which is not conducive to online monitoring. In [23], $T_{\mathrm{j}}$ was obtained by measuring the linear relationship between $V_{\text {ce_on }}$ and $T_{\mathrm{j}}$, whereas in [24], $T_{\mathrm{j}}$ was calculated by the turn-off overshoot voltage. It is worth noting that $T_{\mathrm{j}}$ cannot directly reflect the aging state of the IGBT, but it has a close coupling relationship with other parameters, which are called thermosensitive electrical parameters (TSEPs) $[25,26]$. Almost all the above monitoring parameters for bond wire are TSEPs.

Considering online monitoring capabilities, hardware cost, and measurement accuracy, $V_{\text {ce_on }}$ is most suitable for monitoring the aging state of bond wires [27]. Although $V_{\text {ce_on }}$ is very suitable as the IGBT monitoring parameter, the voltage between the collector and the emitter can be hundreds of times different when the IGBT is turned on and off at high speed, making it difficult to sample $V_{\text {ce_on }}$ online and accurately. In [28], a sampling circuit based on the IGBT, current source, and voltage source is proposed. By modifying the converter's PWM control signal, different currents are injected into the converter during

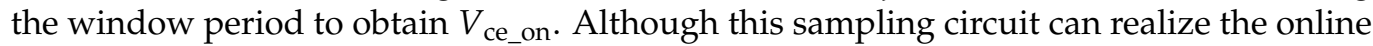
monitoring of the IGBT, it has a significant influence on the converter's working state. In [29], a sampling circuit based on the current source, diode, and MOSFET is proposed which indirectly measures $V_{\text {ce_on }}$ by measuring the voltage at the test point. When the IGBT is on, the test point voltage is the sum of the diode conduction voltage drop, the resistance voltage drop, and the $V_{\text {ce_on }}$. When the IGBT is off, the MOSFET is turned on to shield the high voltage between the collector and the emitter. This sampling circuit also needs to inject current into the test circuit and indirectly measure the $V_{\text {ce_on }}$. All in all, the existing $V_{\text {ce_on }}$ sampling circuit needs to inject current into the converter or modify the control signal, which will not affect the working state of the converter to varying degrees. 
While $V_{\text {ce_on }}$ has a strong correlation with bond wire aging, it also has a coupling relationship with $T_{\mathrm{j}}$. During the operation of the photovoltaic, wind power, and new energy vehicles, $T_{\mathrm{j}}$ of the IGBT module changes all the time, which will interfere with the judgment of the bond wires' aging state. The existing method eliminates the interference of $T_{\mathrm{j}}$ by injecting current into the IGBT module [23,30], which will not be suitable for online monitoring. The authors of [31] calculated the equivalent resistance at the bonding area based on the offline measurement of $V_{\text {ce_on }}$ and evaluated the health status of the independent IGBT module accordingly. Although this method considers the influence of $T_{\mathrm{j}}$, it belongs to the field of IGBT offline reliability evaluation and does not provide a solution for online monitoring under actual working conditions. In general, the existing online monitoring methods are difficult for effectively eliminating the interference of $T_{\mathrm{j}}$.

Motivated by the analysis described above, based on the voltage and current sampling circuit, this paper proposes an online monitoring method for the IGBT bond wire against $T_{\mathrm{j}}$ interference. The method proposed in this paper can non-intrusively monitor IGBT modules online, which can reduce unnecessary downtime for maintenance. The innovation of the sampling circuit is that it can obtain the full-period waveform of $V_{\text {ce_on }}$ varying with the collector current $\left(I_{\mathrm{c}}\right)$ during the modulation period. The circuit cleverly utilizes the current flowing through the IGBT and the corresponding turn-on voltage drop during the IGBT working process, and it does not need to inject additional current into the circuit or modify the control signal to collect aging parameters. It obtains the intersection collector current $\left(I_{\text {int }}\right)$ such that $V_{\text {ce_on }}$ is not disturbed by $T_{\mathrm{j}}$ via the IGBT bond wire aging model and datasheet. Then, it compares the real-time sampling waveforms of $I_{\mathrm{C}}$ and $V_{\text {ce_on }}$ to obtain the collector-emitter on-state voltage corresponding to $I_{\text {int }}\left(V_{\text {ce_int }}\right)$. Finally, the bond wire aging state can be judged based on $V_{\text {ce_int, }}$ which is not interfered with by $T_{\mathrm{j}}$.

This paper is organized as follows. Section 2 establishes the aging model of the IGBT bond wire and selects the $V_{\text {ce_int }}$ value as the aging parameter in combination with the datasheet. Section 3 illustrates the working principle of the sampling circuit and introduces the online monitoring process based on the sampling waveform. Section 4 takes a threephase inverter as an example for experimental verification and uses the method proposed in this paper to monitor the bond wire aging under the interference of DC voltage and $T_{\mathrm{j}}$. Section 5 draws the conclusions.

\section{IGBT Bond Wire Aging Modeling}

\subsection{Bond Wire Aging Mechanism}

The basic internal structure of the IGBT module is shown in Figure 1a. To meet the rated current requirements and improve the performance, the IGBT module is usually composed of multiple IGBT chips in parallel, in which the emitter and gate of the chip and the corresponding terminals need to be connected via bond wires. Due to the large CTE difference between aluminum and silicon materials, the thermal stress on the chip and the bond wire under the action of the temperature field is inconsistent, causing shear stress at the bonding area of the bond wire and the chip [32], which can be expressed as

$$
\varepsilon=L \cdot\left(\alpha_{1}-\alpha_{2}\right) \cdot \Delta T
$$

where $\alpha_{1}$ and $\alpha_{2}$ are the CTE of the bond wire and the silicon chip, $\Delta T$ represents the temperature fluctuation, and $L$ is the length of the bonding area between the bond wire and the silicon chip.

In the actual working process of the IGBT, the continuous thermal stress impact makes the bonding area age, and the specific manifestation is the bond wire's lift-off. As long as one of the bond wires in the IGBT module breaks first, the current passing through the remaining bond wires will increase and bear greater thermal stress impact, which will accelerate the failure of the IGBT device. Therefore, bond wire lift-off is one of the main modes of IGBT failure in practical engineering applications. 


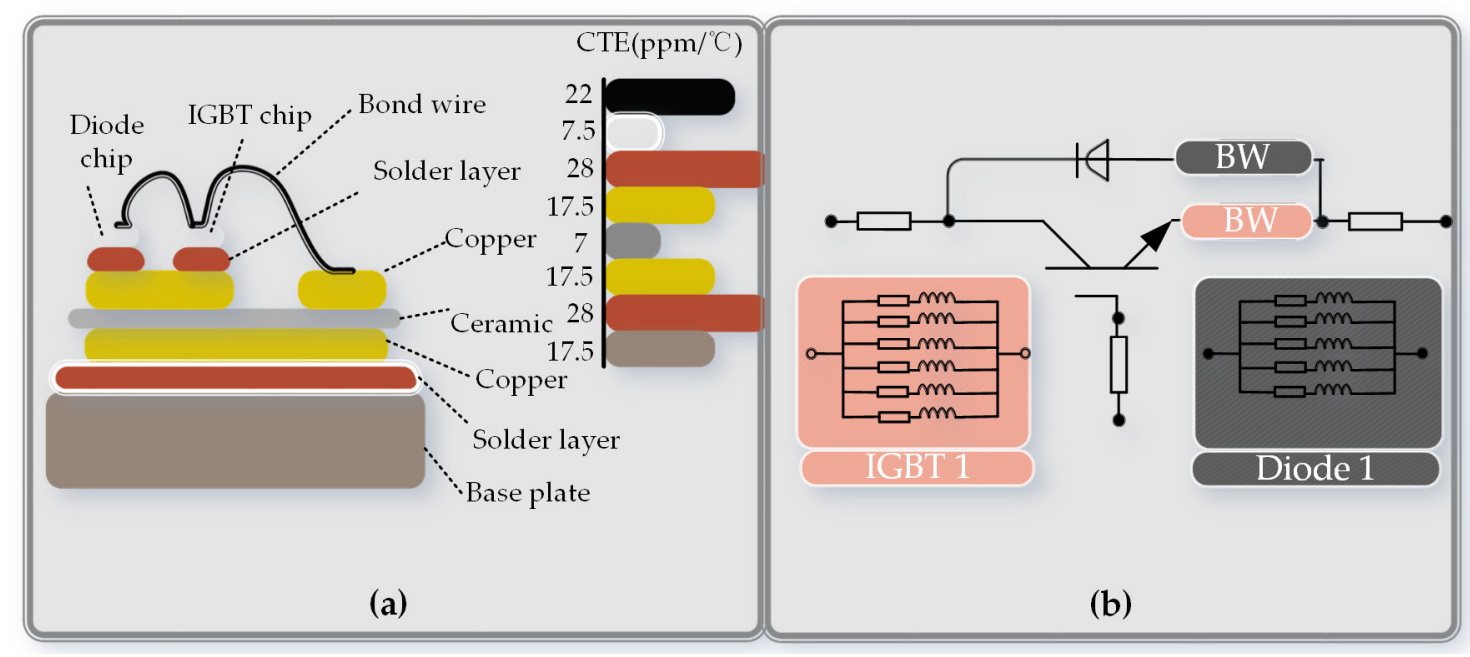

Figure 1. (a) The structure of the IGBT (insulated-gate bipolar transistor) module. (b) Equivalent model of the IGBT bond wires.

\subsection{Bond Wire Aging Model}

Since the $V_{\text {ce_on }}$ of the IGBT module is affected by both aging and $T_{\mathrm{j}}$, it is necessary to exclude the influence of $T_{\mathrm{j}}$ on the $V_{\text {ce_on }}$ to accurately reflect the bond wire aging. In the actual operation of converters, it is difficult to accurately control and measure the internal $T_{\mathrm{j}}$ of the IGBT module, which makes it harder to determine whether the variation in the $V_{\text {ce_on }}$ is caused by $T_{\mathrm{j}}$ or aging.

Taking the FF50R12RT4 half-bridge module as an example, the IGBT in the module contain six bond wires, as shown in Figure $1 \mathrm{~b}$. $V_{\text {ce_on }}$ is affected by $T_{\mathrm{j}}$ and $I_{\mathrm{c}}$ in a healthy state [28], as shown in Equation (2):

$$
V_{\text {ce_on }}=V_{0}-k_{1} \cdot\left(T_{\mathrm{j}}-T_{\mathrm{j} 0}\right)+\left[R_{0}+k_{2} \cdot\left(T_{\mathrm{j}}-T_{\mathrm{j} 0}\right)\right] \cdot I_{\mathrm{C}}
$$

where $V_{0}$ and $R_{0}$ are the on-state voltage and on-state resistance of the IGBT at the reference junction temperature $T_{\mathrm{j} 0}$, respectively, and $k_{1}$ and $k_{2}$ are the temperature coefficients of $V_{0}$ and $R_{0}$, respectively.

When the IGBT bond wires are broken due to thermal stress impact, $R_{0}$ will change, which will affect $V_{\text {ce_on }}$. The equation of $V_{\text {ce_on }}$ under the bond wire aging is as follows:

$$
V_{\text {ce_on }}=V_{0}-k_{1} \cdot\left(T_{\mathrm{j}}-T_{\mathrm{j} 0}\right)+\left[R_{0}+\Delta R+k_{2} \cdot\left(T_{\mathrm{j}}-T_{\mathrm{j} 0}\right)\right] \cdot I_{\mathrm{c}}
$$

where $\Delta R$ represents the variation in the on-state resistance of the IGBT caused by the broken bond wire and $k_{1} \cdot\left(T_{\mathrm{j}}-T_{\mathrm{j} 0}\right)$ is inversely proportional to $\left(T_{\mathrm{j}}-T_{\mathrm{j} 0}\right)$, whereas $\left[R_{0}+\right.$ $\left.\Delta R+k_{2} \cdot\left(T_{\mathrm{j}}-T_{\mathrm{j} 0}\right)\right] \cdot I_{\mathrm{c}}$ is directly proportional to $\left(T_{\mathrm{j}}-T_{\mathrm{j} 0}\right)$. The contribution of the former is negative, while the contribution of the latter is positive. There is a value $I_{\text {int }}$, where $V_{\text {ce_on }}$ is not affected by the $T_{\mathrm{j}}$. When $I_{\mathrm{C}}=I_{\text {int }}, V_{\text {ce_on }}$ at this time is called $V_{\text {ce_int, }}$ as shown in Equation (4), where $k_{1} \cdot\left(T_{\mathrm{j}}-T_{\mathrm{j} 0}\right)$ and $k_{2} \cdot\left(T_{\mathrm{j}}-T_{\mathrm{j} 0}\right) \cdot I_{\mathrm{C}}$ cancel each other out and $V_{\text {ce_int }}$ is only affected by $\left(R_{0}+\Delta R\right) \cdot I_{\mathrm{C}}$ :

$$
V_{\text {ce_int }}=V_{0}-k_{1} \cdot\left(T_{\mathrm{j}}-T_{\mathrm{j} 0}\right)+\left(R_{0}+\Delta R\right) \cdot I_{\mathrm{C}}+k_{2} \cdot\left(T_{\mathrm{j}}-T_{\mathrm{j} 0}\right) \cdot I_{\mathrm{C}}
$$

Therefore, $V_{\text {ce_int }}$ can accurately reflect the voltage drop change caused by the bond wire aging and is not affected by $T_{\mathrm{j}}$, which can be regarded as the monitoring parameter of bond wire aging.

Referring to the datasheet of the FF50R12RT4 IGBT module, the typical values of $I_{\text {int }}$ and $V_{\text {ce_int }}$ can be obtained according to their output characteristic curves, as shown in Figure 2. When $T_{\mathrm{j}}$ is $25^{\circ} \mathrm{C}, 125^{\circ} \mathrm{C}$ or $150^{\circ} \mathrm{C}$, the output characteristic curve of the IGBT 
module will have an intersection where $I_{\text {int }}=12 \mathrm{~A}$. When $I_{\mathrm{C}}=I_{\text {int }}, V_{\text {ce_int }}$ is not affected by $T_{\mathrm{j}}$, which is consistent with the previous discussion.

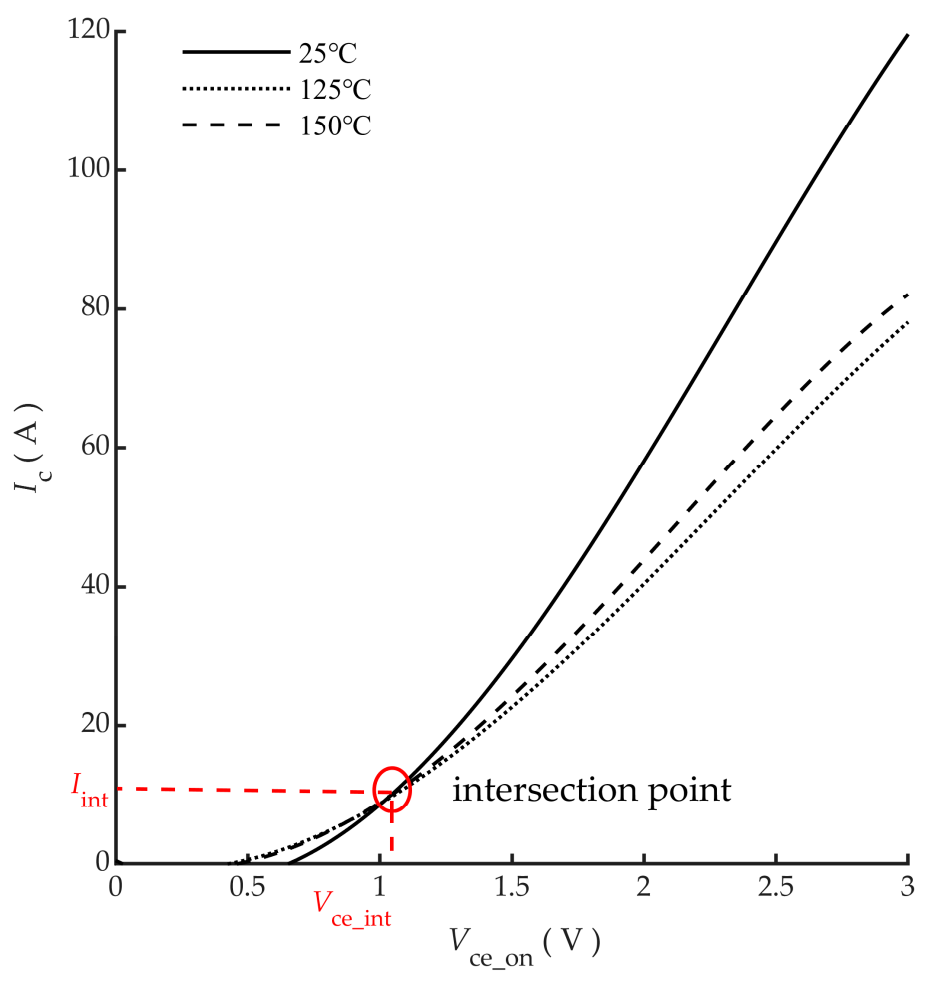

Figure 2. IGBT output characteristic curve.

\section{Online Monitoring of IGBT Bond Wire Aging}

In this paper, a three-phase inverter is taken as an example to illustrate the working principle of the proposed anti-interference online monitoring method for bond wire aging. It will be explained in two parts: the sampling circuit and online monitoring.

\subsection{Sampling Circuit}

Although $V_{\text {ce_on }}$ is very suitable as an IGBT aging parameter, the voltage between the collector and the emitter can be hundreds of times different when the IGBT is turned on and off at a high speed, making it difficult to sample $V_{\text {ce_on }}$ online and accurately. The

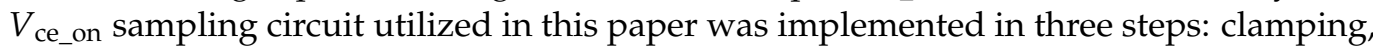
filtering, and amplifying, as presented in Figure 3. Clamping refers to the high-voltage shielding between the collector and emitter during the turn-off period of the IGBT via the switching of two MOSFETs $\left(\mathrm{M}_{1}\right.$ and $\left.\mathrm{M}_{2}\right)$. Take the U-phase upper leg IGBT (S1) as an example to explain the working principle. When $S 1$ is turned on, $M_{1}$ is turned on so that the voltage sampling channel is turned on, thereby sampling $V_{\text {ce_on. When } \mathrm{S} 1 \text { is turned }}$ off, $\mathrm{M}_{2}$ is turned on, so the voltage sampling channel is clamped to the ground potential, thereby shielding the high voltage between collector and emitter. The specific control diagram is shown in Table 1.

Table 1. Voltage sampling circuit drive signal.

\begin{tabular}{ccccc}
\hline Switch & $\mathbf{M}_{\mathbf{1}}$ & $\mathbf{M}_{\mathbf{2}}$ & $\mathbf{M}_{\mathbf{3}}$ & $\mathbf{M}_{\mathbf{4}}$ \\
\hline S1 on & 1 & 0 & 0 & 0 \\
\hline S1 off & 0 & 1 & 0 & 0 \\
\hline S2 on & 0 & 0 & 1 & 0 \\
\hline S2 off & 0 & 0 & 0 & 1 \\
\hline
\end{tabular}




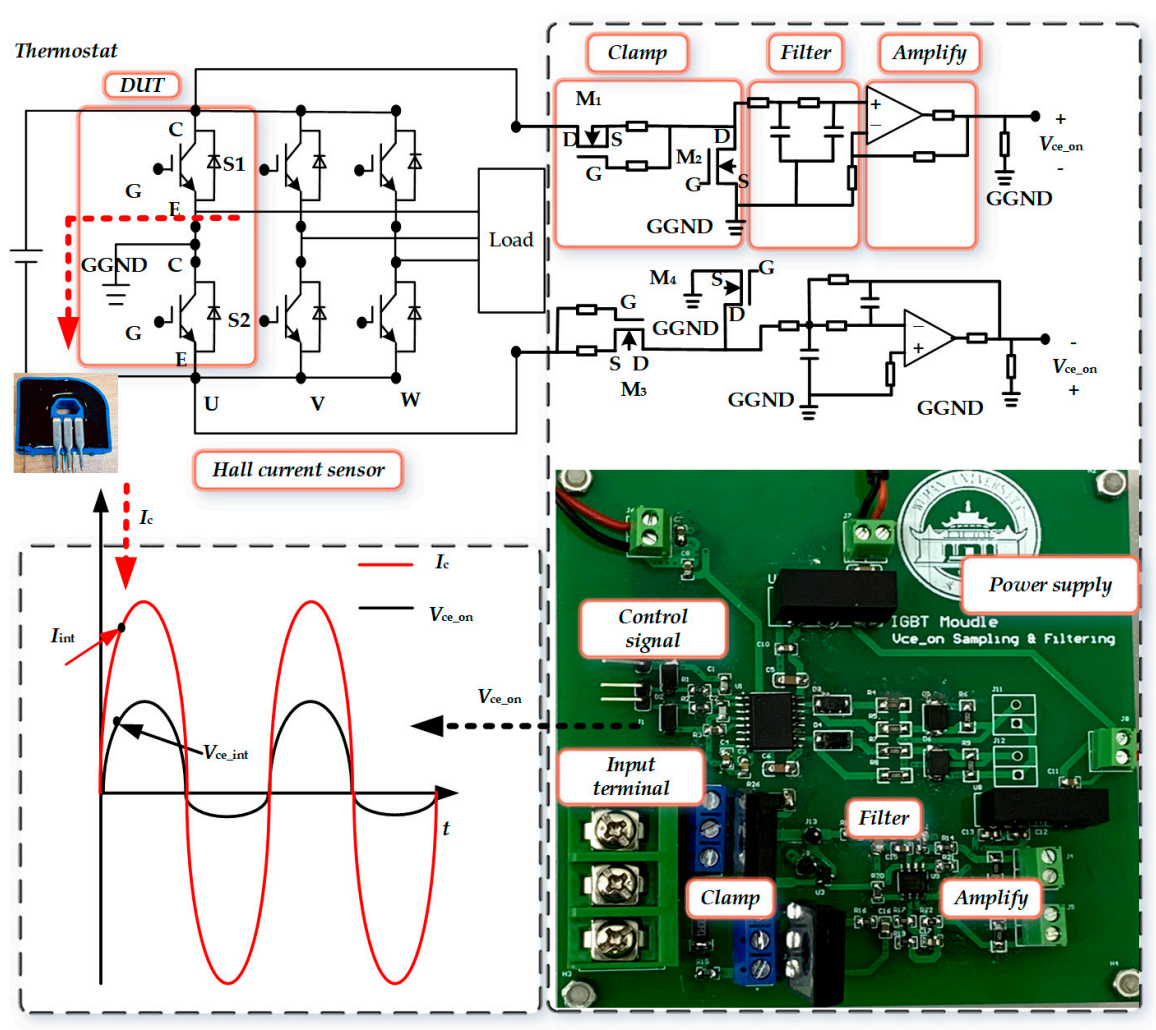

Figure 3. Working principle of the voltage and current sampling circuit.

Filtering is related to eliminating the noise contained in the waveform obtained after clamping by a second-order RC circuit, but it also produces a certain degree of attenuation. Amplification refers to the use of an operational amplifier to compensate for the waveform attenuation caused by the filter part, which ensures the accuracy of the sampled waveform. As for the current sampling part, Hall current sensors are used for synchronous sampling. The voltage and current waveforms obtained by the sampling circuit are presented in Figure 3. By comparing the waveforms, $I_{\text {int }}$ and $V_{\text {int }}$ can be further collected to prepare for condition monitoring.

\subsection{Online Monitoring}

Based on the above sampling circuit, this paper proposes an online monitoring method for IGBT bond wire aging, as illustrated in Figure 4. First, the voltage and current sampling circuits are used to collect the $V_{\text {ce_on }}$ and $I_{\mathrm{c}}$ waveforms of the three-phase inverter system in real time. Second, considering the impact of fluctuations on the DC side or the load side on $I_{C}$, the amplitude of $I_{C}$ is compared with that of $I_{\text {int }}$. Only when the amplitude of $I_{\mathrm{C}}$ is greater than $I_{\text {int }}$ is the corresponding $V_{\text {ce_int }}$ sampling performed. Then, $V_{\text {ce_int }}$ is compared with the aging threshold to judge the aging state of the bond wires. Finally, when the aging state reaches the failure threshold set in advance, a failure warning is triggered to the control system. The measurement of the aging threshold will be described in detail in the next section. 


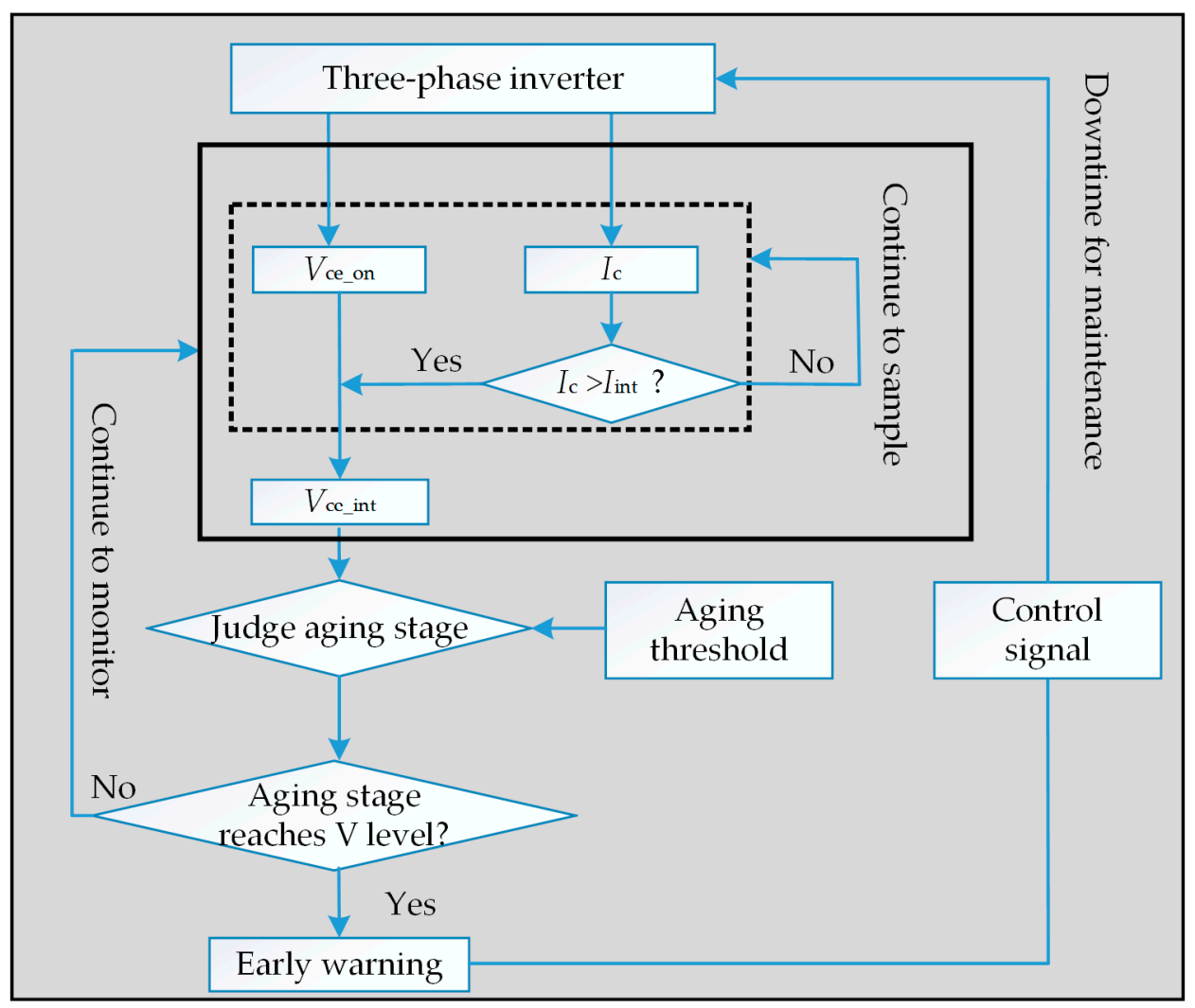

Figure 4. Voltage and current sampling circuit.

\section{Experiment and Result Analysis}

In order to verify the effectiveness of the method proposed in this paper, an experimental platform for aging monitoring was built as presented in Figure 5, which included the DC power supply, three-phase inverter circuit, sampling circuit, thermostat, IR thermal imager, and control unit. The experimental parameter settings are listed in Table 2. It is worth noting that the voltage and current signals collected in this paper were input into RT-LAB for high-precision A/D conversion.

Table 2. Experimental platform parameter settings.

\begin{tabular}{cc}
\hline Parameters & Values \\
\hline Switching frequency $\left(f_{\text {sw }}\right)$ & $20 \mathrm{kHz}$ \\
Output frequency $(f)$ & $50 \mathrm{~Hz}$ \\
IGBT module type & FF50R12RT4 \\
IR type & Testo 865 \\
Thermostat type & JF- 966 \\
Junction temperature $\left(T_{\mathrm{j}}\right)$ & $25-75^{\circ} \mathrm{C}$ \\
Number of broken bond wires & $0-4$ \\
Resolution of ADC & $16-\mathrm{bit}$ \\
Gain band width of amplifier & $4 \mathrm{MHz}$ \\
\hline
\end{tabular}



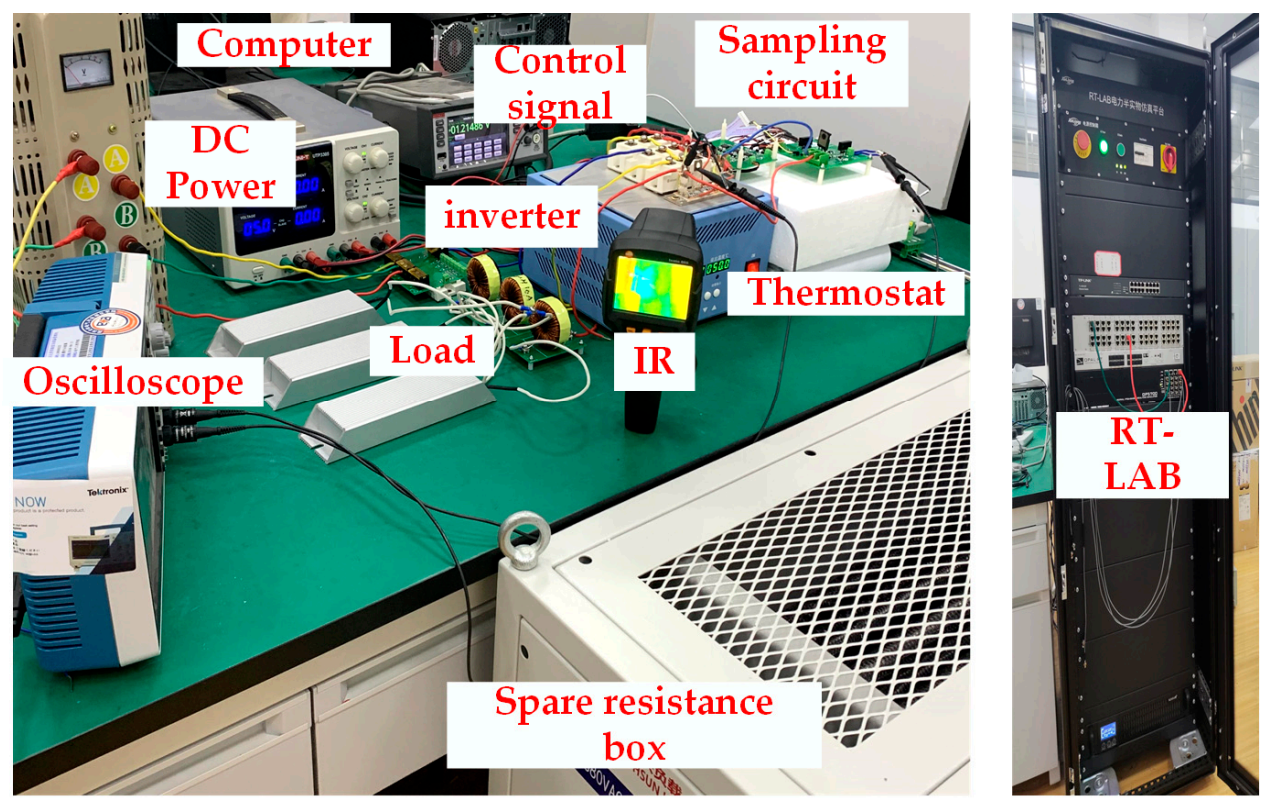

Figure 5. Aging monitoring platform.

\subsection{Sampling under DC Voltage Fluctuations}

In the actual working process of the inverter, it will be subjected to electrical disturbances on the load or DC voltage side, which will cause $I_{C}$ fluctuations. In order to prove that the sampling circuit could still maintain excellent working performance under this disturbance, this paper carried out relevant sampling under the condition of DC voltage fluctuation, as shown in Figure 6. It could be found that the $V_{\text {ce_on }}$ waveform could follow the fluctuation of $I_{\mathrm{c}}$, which indicates that the sampling circuit had good anti-interference performance. The red dotted line marks $I_{\text {int }}$ and its corresponding $V_{\text {int }}$, which are the basis for subsequent condition monitoring.

In the case of $T_{\mathrm{j}}=25^{\circ} \mathrm{C}, V_{\text {ce_int }}$ was selected when the IGBT was fully healthy $\left(V_{\text {ce_int } 0}\right)$ as the healthy reference value. When 1-4 bond wires were broken (see Figure 7), the corresponding $V_{\text {ce_int }}$ was sampled, and Equation (5) was used to calculate the deviation percentage of each aging stage $\left(\Delta V_{\text {ce_int }}\right)$, which was regarded as the aging indicator, as listed in Table 2. For subsequent comparison, this paper also measured the $V_{\text {ce_on }}$ amplitude voltage $\left(V_{\text {ce_fo }}\right)$ in the healthy state and calculated the deviation percentage of each aging stage $\left(\Delta V_{\text {ce_f }}\right)$ according to Equation (6), as listed in Table 3. The two dashed lines marked in Figure 7 are the health reference values. After measurement, $V_{\text {ce_into } 0}$ and $V_{\text {ce_fo }}$ could be obtained as $1.05 \mathrm{~V}$ and $1.32 \mathrm{~V}$, respectively:

$$
\begin{gathered}
\Delta V_{\text {ce_int }}=\left(V_{\text {ce_int }}-V_{\text {ce_int } 0}\right) / V_{\text {ce_int } 0} \\
\Delta V_{\text {ce_f }}=\left(V_{\text {ce_f }}-V_{\text {ce_f } 0}\right) / V_{\text {ce_f } 0}
\end{gathered}
$$

Table 3. Aging threshold.

\begin{tabular}{cccc}
\hline $\begin{array}{c}\text { Number of Broken } \\
\text { Bond Wires }\end{array}$ & $\begin{array}{c}\text { Aging Threshold for } \\
\boldsymbol{V}_{\text {ce_int }}\end{array}$ & $\begin{array}{c}\text { Aging Threshold for } \\
\boldsymbol{V}_{\text {ce_f }}\end{array}$ & Aging States \\
\hline 0 & $<0.57 \%$ & $<0.68 \%$ & I \\
1 & $0.58-1.25 \%$ & $0.69-1.14 \%$ & II \\
2 & $1.26-2.68 \%$ & $1.15-2.58 \%$ & III \\
3 & $2.69-4.89 \%$ & $2.59-4.86 \%$ & VI \\
4 & $>4.90 \%$ & $>4.86 \%$ & V \\
\hline
\end{tabular}




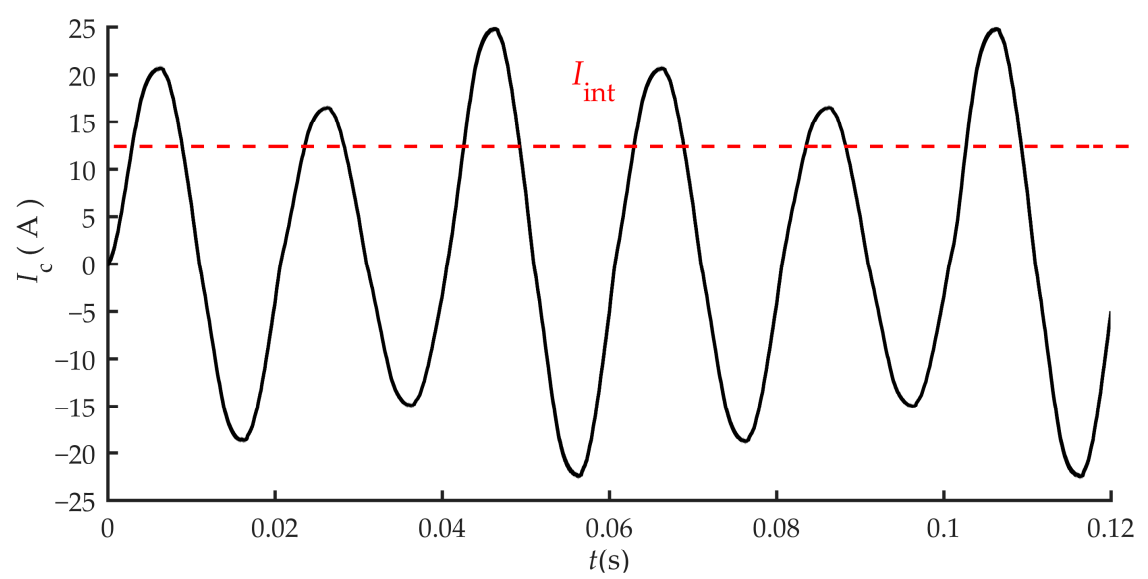

(a)

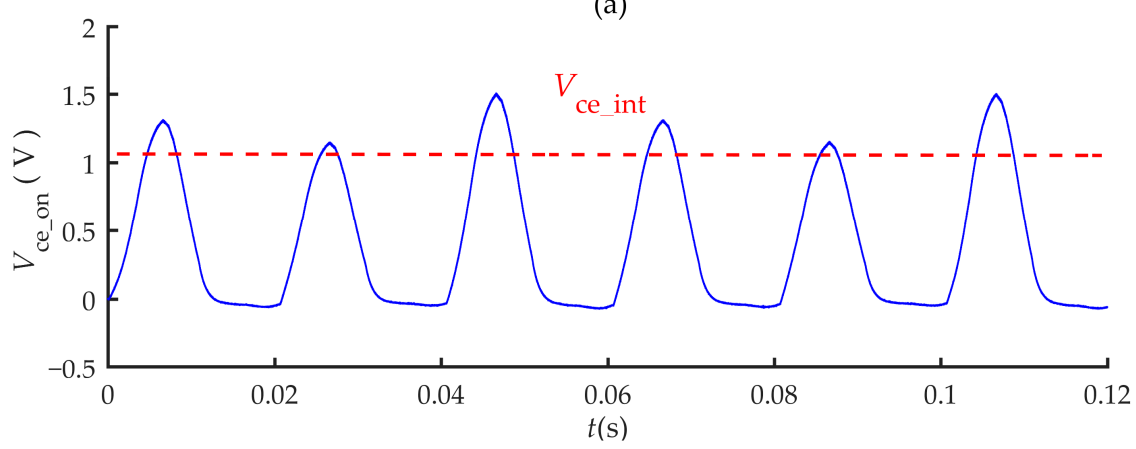

(b)

Figure 6. (a) The waveform of $I_{\mathrm{c}}$. (b) The waveform of $V_{\text {ce_on. }}$.

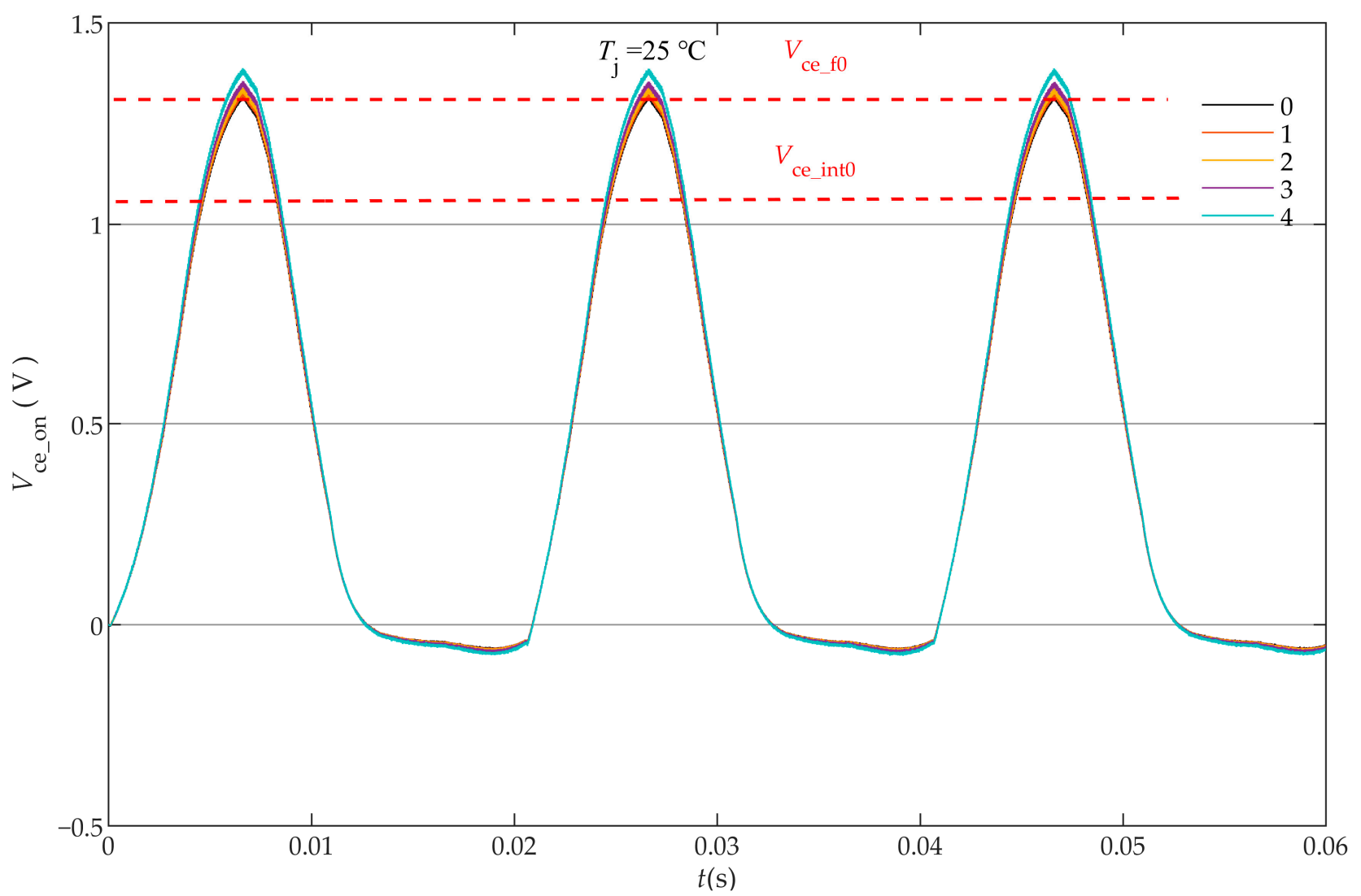

Figure 7. Online monitoring results with different broken bond wires in the case of $T_{\mathrm{j}}=25^{\circ} \mathrm{C}$. 


\subsection{Junction Temperature Interference}

Taking three bond wires' lift-off as an example to illustrate the interference of $T_{\mathrm{j}}$, the $T_{\mathrm{j}}$ of $\mathrm{S} 1$ was stabilized at $50{ }^{\circ} \mathrm{C}$ and $75^{\circ} \mathrm{C}$ by adjusting the thermostat to simulate $T_{\mathrm{j}}$ fluctuations. In the above four cases, the $V_{\text {ce_on }}$ waveform is shown in Figure 8. It can be found that the waveform near $V_{\text {ce_int }}$ was not affected by $T_{\mathrm{j}}$. $V_{\text {ce_int }}$ did not deviate with the increase in $T_{\mathrm{j}}$, which could accurately reflect the aging state of the bond wires. In addition, the waveform near $V_{\text {ce_f }}$ was most disturbed by $T_{\mathrm{j}} . V_{\text {ce_f }}$ had a significant deviation as $V_{\text {ce_f }}$ increased, and the maximum deviation reached $60 \mathrm{mV}$. In summary, selecting $\mathrm{V}_{\mathrm{ce}}$ as the aging indicator could achieve resistance to the interference of $T_{\mathrm{j}}$.

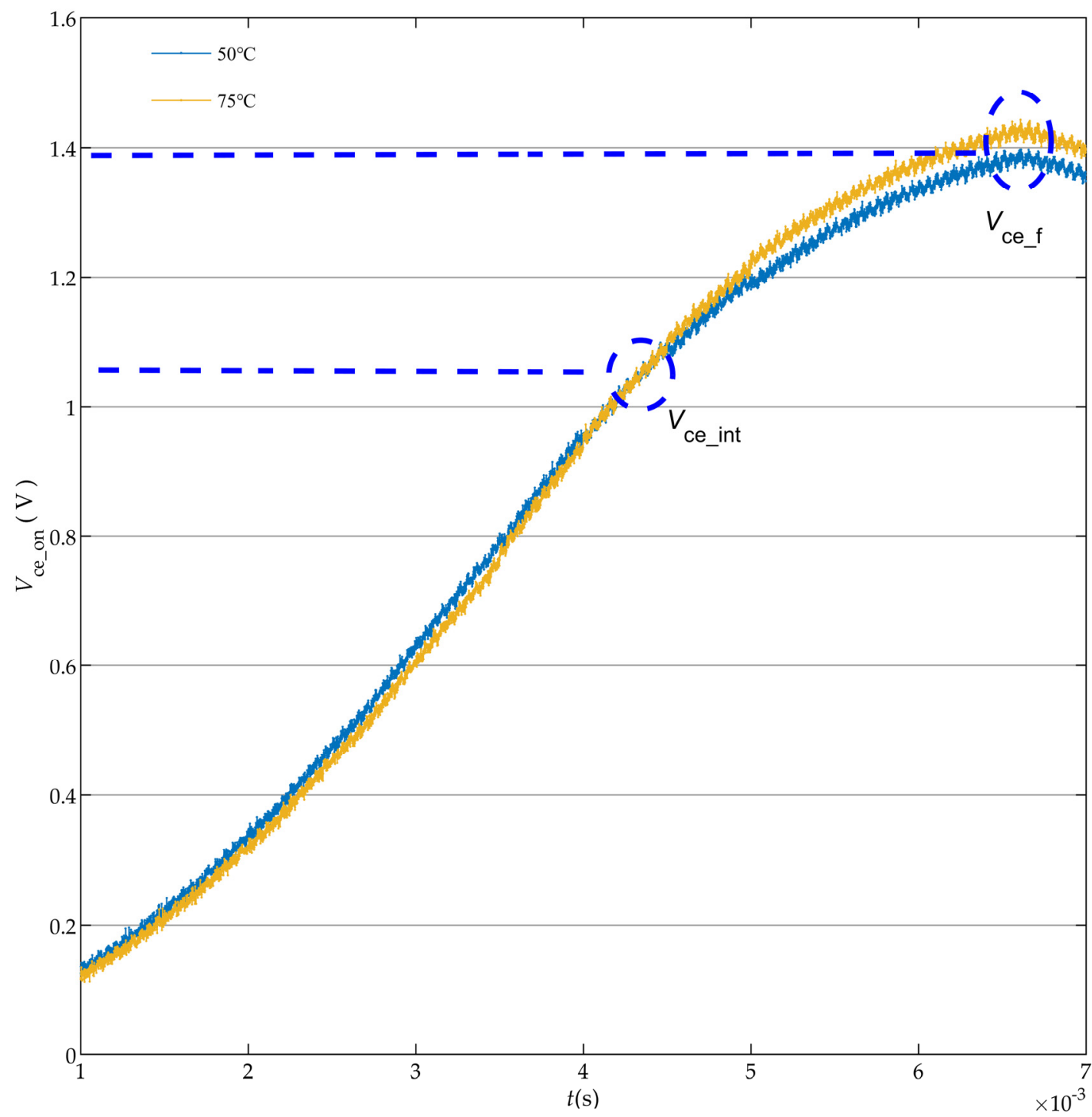

Figure 8. Online monitoring results with different junction temperatures.

\subsection{Aging Monitoring Results}

In order to show that the monitoring method proposed in this paper could eliminate the interference of $T_{\mathrm{j}}$, in the case of $T_{\mathrm{j}}=75^{\circ} \mathrm{C}$, the sampling circuit was used to measure $V_{\text {ce_on }}$ under different bond wire aging stages, as shown in Figure 9. Using Equations (5) and (6), the aging index of each aging stage was calculated. The aging indicators with the previously determined aging threshold (see Table 3) were compared to judge the current aging state, as shown in Table 4 . 


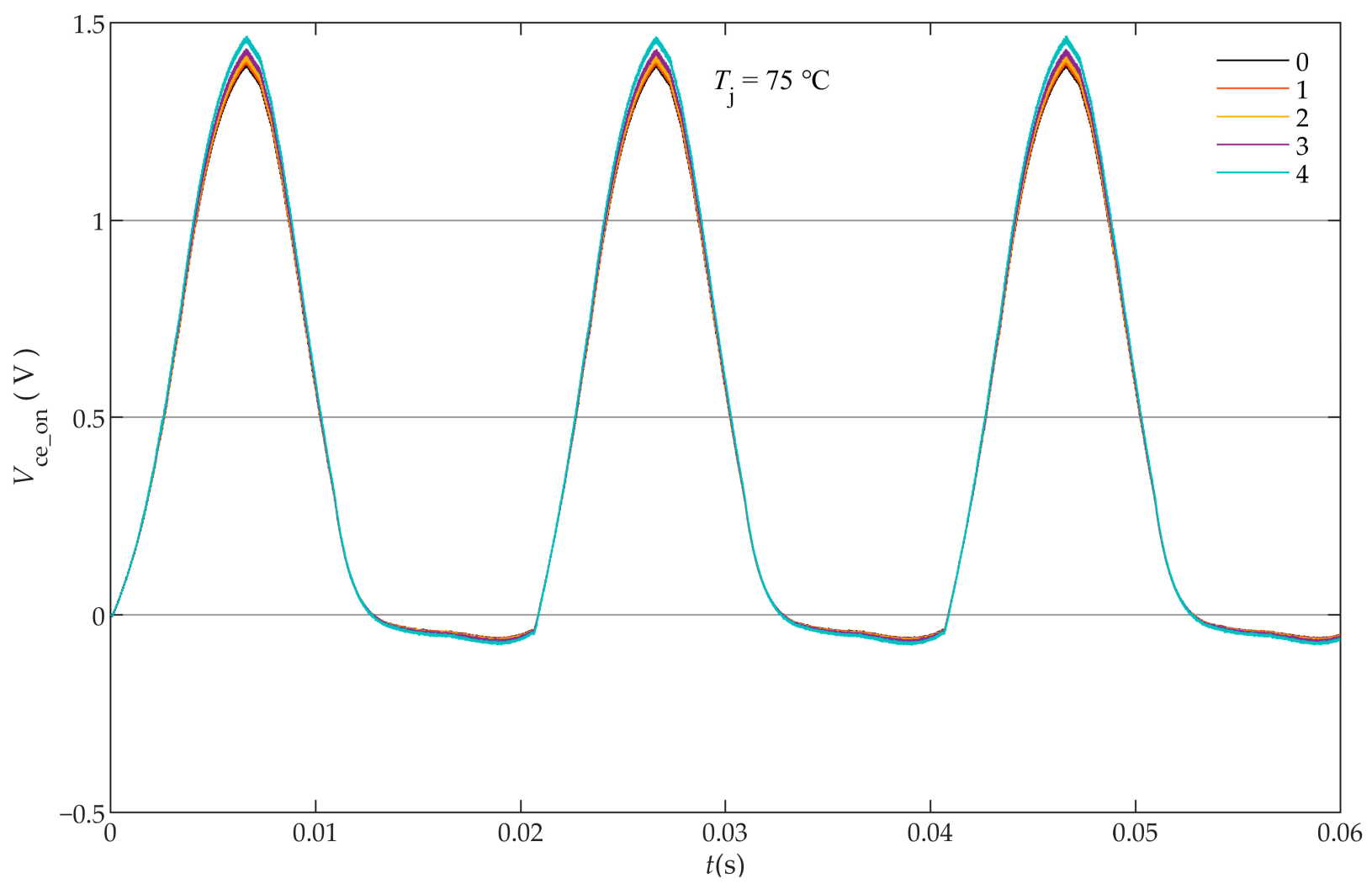

Figure 9. Online monitoring results with different broken bond wires in the case of $T_{\mathrm{j}}=75^{\circ} \mathrm{C}$.

Table 4. Aging monitoring results in the case of $T_{\mathrm{j}}=75^{\circ} \mathrm{C}$.

\begin{tabular}{ccccc}
\hline $\begin{array}{c}\text { Number of Broken } \\
\text { Bond Wires }\end{array}$ & $\boldsymbol{V}_{\text {ce_int }}(\mathbf{V})$ & $\boldsymbol{\Delta} \boldsymbol{V}_{\mathbf{c e} \_ \text {int }}$ & $\boldsymbol{V}_{\text {ce_f }}(\mathbf{V})$ & $\boldsymbol{\Delta} \boldsymbol{V}_{\text {ce_f }_{-}}$ \\
\hline 0 & 1.052 & $0.19 \%, \mathrm{I}$ & 1.397 & $5.83 \%, \mathrm{~V}$ \\
1 & 1.059 & $0.86 \%, \mathrm{II}$ & 1.402 & $6.21 \%, \mathrm{~V}$ \\
2 & 1.068 & $1.71 \%, \mathrm{III}$ & 1.412 & $6.97 \%, \mathrm{~V}$ \\
3 & 1.085 & $3.33 \%, \mathrm{IV}$ & 1.429 & $8.26 \%, \mathrm{~V}$ \\
4 & 1.111 & $5.81 \%, \mathrm{~V}$ & 1.462 & $10.76 \%, \mathrm{~V}$ \\
\hline
\end{tabular}

When $T_{\mathrm{j}}$ rose from $25^{\circ} \mathrm{C}$ to $75^{\circ} \mathrm{C}, V_{\text {ce_int }}$ had a slight deviation compared with $V_{\text {ce_int } 0}$ but $\Delta V_{\text {ce_int }}$ could still accurately reflect the current aging state. On the contrary, $V_{\text {ce_f }}$ had a large deviation compared with $V_{\text {ce_fo }}$, and $\Delta V_{\text {ce_f }}$ was far away from the current aging state. For example, when the IGBT was in aging stage II, $\Delta V_{\text {ce_int }}$ was $0.86 \%$, which was judged as aging state I according to the aging thresholds. However, $\Delta V_{\text {ce_f }}$ was $6.21 \%$, which was misjudged as aging stage $\mathrm{V}$.

In order to compare the aging monitoring results more intuitively, different color blocks in Figure 10 are used to indicate the different aging stages. It can be clearly seen that the monitoring results based on $\Delta V_{\text {ce_int }}$ could accurately distinguish each aging stage, while the monitoring results based on $\Delta V_{\text {ce_f }}$ deviated far from the actual situation. In general, $V_{\text {ce_int }}$ had good resistance to the interference of $T_{\mathrm{j}}$. For this three-phase inverter system, when the monitoring circuit detected that the aging indicator exceeded $4.90 \%$, the aging state of the IGBT bond wire was judged as stage V. At this time, a shutdown maintenance signal was triggered in the control system. 
Aging threshold

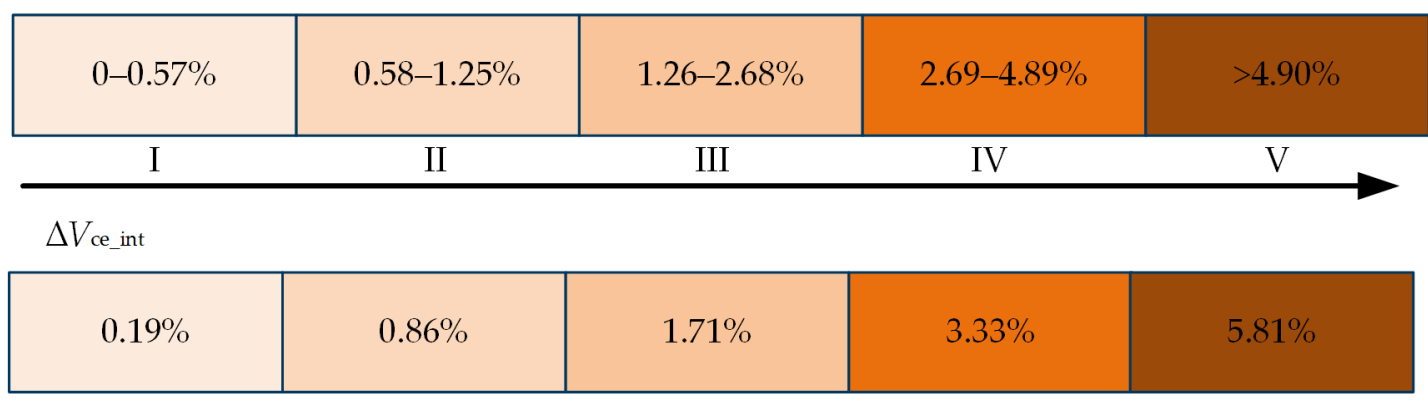

$\Delta V_{\text {ce } \_f}$

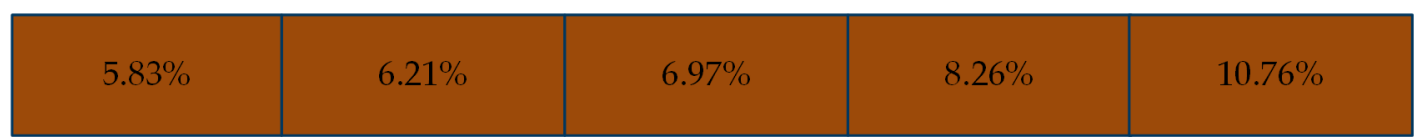

Figure 10. Comparison of aging monitoring results.

\section{Conclusions}

The aging parameter $V_{\text {ce_int, }}$, which is not affected by $T_{\mathrm{j}}$, is obtained by combining the IGBT aging model and the datasheet. Moreover, $V_{\text {ce_int }}$ is collected in real time to judge the aging state of the IGBT bond wire by comparing the $I_{\mathrm{C}}$ and $V_{\text {ce_on }}$ waveforms. Different from the existing method, this method cleverly utilizes the current flowing through the IGBT and the corresponding turn-on voltage drop during the IGBT working process, and it does not need to inject additional current into the circuit or modify the control signal to collect the aging parameters. In addition, the anti-interference online monitoring method proposed in this paper can reduce downtime for maintenance.

The experimental results output by RT-LAB prove that the method proposed in this paper can judge the aging state of the IGBT bond wire in the three-phase inverter under the condition of DC voltage disturbance and junction temperature disturbance. It is worth noting that this paper only introduced this method's application in a three-phase inverter system, and it also applies to other power electronic converters.

Author Contributions: Conceptualization, methodology, software, validation, formal analysis, investigation, and resources, C.W. and Y.H.; data curation, writing-original draft preparation, Y.J.; writing-review and editing and visualization, L.L. All authors have read and agreed to the published version of the manuscript.

Funding: This research was funded by the National Natural Science Foundation of China (Grant No. 51977153, 51977161, 51577046), the Fundamental Research Funds for the Central Universities of China (Grant No. 2042021kf0233), the State Key Program of the National Natural Science Foundation of China (Grant No. 51637004), the national key research and development plan "important scientific instruments and equipment development" of China (Grant No. 2016YFF0102200), "smart grid technology and equipment" of China (Grant No. 2020YFB0905905), the Equipment Research Project in Advance of China (Grant No. 41402040301), and the Wuhan Science and Technology Plan Project (Grant No. 20201G01).

Conflicts of Interest: The authors declare no conflict of interest.

\section{References}

1. Choi, U.-M.; Blaabjerg, F.; Lee, K.-B. Study and Handling Methods of Power IGBT Module Failures in Power Electronic Converter Systems. IEEE Trans. Power Electron. 2015, 30, 2517-2533. [CrossRef]

2. Li, H.; Liao, X.; Zeng, Z.; Hu, Y.; Li, Y.; Liu, S.; Ran, L. Thermal Coupling Analysis in a Multichip Paralleled IGBT Module for a DFIG Wind Turbine Power Converter. IEEE Trans. Energy Convers. 2016, 32, 80-90. [CrossRef]

3. Lai, W.; Wang, Z.; Hu, Y.; Chen, M.; Xia, H.; Luo, D.; Wei, Y.; Gao, B.; Chen, Y. Evaluation of IGBT Module Remaining Lifetime in Wind Power Converters Considering Impacts of Failure Location. IEEE Trans. Electron Devices 2021, 68, 1810-1818. [CrossRef] 
4. Reigosa, P.D.; Wang, H.; Yang, Y.; Blaabjerg, F. Prediction of Bond Wire Fatigue of IGBTs in a PV Inverter under a Long-Term Operation. IEEE Trans. Power Electron. 2015, 31, 7171-7182. [CrossRef]

5. Ji, B.; Song, X.; Cao, W.; Pickert, V.; Hu, Y.; Mackersie, J.W.; Pierce, G. In Situ Diagnostics and Prognostics of Solder Fatigue in IGBT Modules for Electric Vehicle Drives. IEEE Trans. Power Electron. 2015, 30, 1535-1543. [CrossRef]

6. Buticchi, G.; Barater, D.; Costa, L.F.; Liserre, M. A PV-Inspired Low-Common-Mode Dual-Active-Bridge Converter for Aerospace Applications. IEEE Trans. Power Electron. 2018, 33, 10467-10477. [CrossRef]

7. Yang, S.; Xiang, D.; Bryant, A.; Mawby, P.; Ran, L.; Tavner, P. Condition Monitoring for Device Reliability in Power Electronic Converters: A Review. IEEE Trans. Power Electron. 2010, 25, 2734-2752. [CrossRef]

8. Oh, H.; Han, B.; McCluskey, P.; Han, C.; Youn, B.D. Physics-of-Failure, Condition Monitoring, and Prognostics of Insulated Gate Bipolar Transistor Modules: A Review. IEEE Trans. Power Electron. 2015, 30, 2413-2426. [CrossRef]

9. Abuelnaga, A.; Narimani, M.; Bahman, A.S. A Review on IGBT Module Failure Modes and Lifetime Testing. IEEE Access. 2021, 9 , 9643-9663. [CrossRef]

10. Hu, K.; Liu, Z.; Yang, Y.; Iannuzzo, F.; Blaabjerg, F. Ensuring a Reliable Operation of Two-Level IGBT-Based Power Converters: A Review of Monitoring and Fault-Tolerant Approaches. IEEE Access. 2020, 8, 89988-90022. [CrossRef]

11. Wang, H.; Liserre, M.; Blaabjerg, F.; Rimmen, P.D.P.; Jacobsen, J.B.; Kvisgaard, T.; Landkildehus, J. Transitioning to Physics-ofFailure as a Reliability Driver in Power Electronics. IEEE J. Emerg. Sel. Top. Power Electron. 2014, 2, 97-114. [CrossRef]

12. Sabbah, W.; Arabi, F.; Avino-Salvado, O.; Buttay, C.; Théolier, L.; Morel, H. Lifetime of power electronics interconnections in accelerated test conditions: High temperature storage and thermal cycling. Microelectron. Reliab. 2017, 76-77, 444-449. [CrossRef]

13. Hanif, A.; Devoto, D.; Khan, F.H. Bond Wire Damage Detection and SOH Estimation of a Dual-Pack IGBT Power Module Using Active Power Cycling and Reflectometry. IEEE Trans. Power Electron. 2019, 35, 6761-6772. [CrossRef]

14. Gonzalez-Hernando, F.; San-Sebastian, J.; Garcia-Bediaga, A.; Arias, M.; Iannuzzo, F.; Blaabjerg, F. Wear-Out Condition Monitoring of IGBT and mosfet Power Modules in Inverter Operation. IEEE Trans. Ind. Appl. 2019, 55, 6184-6192. [CrossRef]

15. Sun, P.; Gong, C.; Du, X.; Peng, Y.; Wang, B.; Zhou, L. Condition Monitoring IGBT Module Bond Wires Fatigue Using Short-Circuit Current Identification. IEEE Trans. Power Electron. 2016, 32, 3777-3786. [CrossRef]

16. Zhou, L.; Zhou, S.; Xu, M. Investigation of gate voltage oscillations in an IGBT module after partial bond wires lift-off. Microelectron. Reliab. 2013, 53, 282-287. [CrossRef]

17. Zhou, S.; Zhou, L.; Sun, P. Monitoring Potential Defects in an IGBT Module Based on Dynamic Changes of the Gate Current. IEEE Trans. Power Electron. 2013, 28, 1479-1487. [CrossRef]

18. Wang, K.; Zhou, L.; Sun, P.; Du, X. Monitoring Bond Wires Fatigue of Multichip IGBT module Using Time Duration of The Gate Charge. IEEE Trans. Power Electron. 2020, 36, 888-897. [CrossRef]

19. Mandeya, R.; Chen, C.; Pickert, V.; Naayagi, R.T.; Ji, B. Gate-Emitter Pre-threshold Voltage as a Health-Sensitive Parameter for IGBT Chip Failure Monitoring in High-Voltage Multichip IGBT Power Modules. IEEE Trans. Power Electron. 2018, 34, 9158-9169. [CrossRef]

20. Choi, U.-M.; Blaabjerg, F.; Jorgensen, S.; Munk-Nielsen, S.; Rannestad, B. Reliability Improvement of Power Converters by Means of Condition Monitoring of IGBT Modules. IEEE Trans. Power Electron. 2017, 32, 7990-7997. [CrossRef]

21. Choi, U.-M.; Blaabjerg, F. Separation of Wear-Out Failure Modes of IGBT Modules in Grid-Connected Inverter Systems. IEEE Trans. Power Electron. 2017, 33, 6217-6223. [CrossRef]

22. Sathik, M.H.M.; Sundararajan, P.; Sasongko, F.; Pou, J.; Natarajan, S. Comparative Analysis of IGBT Parameters Variation Under Different Accelerated Aging Tests. IEEE Trans. Electron Devices 2020, 67, 1098-1105. [CrossRef]

23. Wang, X.; Sun, P.; Sun, L.; Luo, Q.; Du, X. Online Condition Monitoring for Bond Wire Degradation of IGBT Modules in Three-Level Neutral-Point-Clamped Converters. IEEE Trans. Ind. Electron. 2021, 68, 7474-7484. [CrossRef]

24. Yang, Y.; Zhang, P. In situ IGBT Junction Temperature Estimation Method via a Bond Wire Degradation Independent Parameter Turn-off Vce Overshoot. IEEE Trans. Ind. Electron. 2020, PP, 1. [CrossRef]

25. Zhang, J.; Du, M.; Jing, L.; Wei, K.; Hurley, W.G. IGBT Junction Temperature Measurements: Inclusive of Dynamic Thermal Parameters. IEEE Trans. Device Mater. Reliab. 2019, 19, 333-340. [CrossRef]

26. Avenas, Y.; Dupont, L.; Khatir, Z. Temperature Measurement of Power Semiconductor Devices by Thermo-Sensitive Electrical Parameters-A Review. IEEE Trans. Power Electron. 2012, 27, 3081-3092. [CrossRef]

27. Fang, X.; Lin, S.; Huang, X.; Lin, F.; Yang, Z.; Igarashi, S. A review of data-driven prognostic for IGBT remaining useful life. Chin. J. Electr. Eng. 2018, 4, 73-79. [CrossRef]

28. Ma, M.; Ji, B.; Han, J.; Zhan, M.; Xiang, N. In-situ health monitoring of IGBT modules of an on-line medium-voltage inverter system using for industrial Internet of Things. CSEE J. Power Energy Syst. 2020, 6, 638-648. [CrossRef]

29. Yang, Y.; Zhang, Q.; Zhang, P. A Fast IGBT Junction Temperature Estimation Approach Based on ON-State Voltage Drop. IEEE Trans. Ind. Appl. 2021, 57, 685-693. [CrossRef]

30. Ji, B.; Pickert, V.; Cao, W.; Zahawi, B. In Situ Diagnostics and Prognostics of Wire Bonding Faults in IGBT Modules for Electric Vehicle Drives. IEEE Trans. Power Electron. 2013, 28, 5568-5577. [CrossRef]

31. He, Y. IGBT Module Reliability Evaluation Method and Device Based on Bonding Lead Degradation. C.N. Patent 111,856,233B, 27 April 2021.

32. Ciappa, M. Selected failure mechanisms of modern power modules. Microelectron. Reliab. 2002, 42, 653-667. [CrossRef] 